\title{
国内外生物技术安全管理机制 ${ }^{*}$
}

\author{
桑卫国 马克平 魏 伟 \\ (中国科学院植物研究所植物生态学与生物多样性保育中心，北京 100093 )
}

摘 要 综述了国内外生物安全管理机制,特别是生物技术安全管理机构和运行方式,分别就国际组 织、美洲、欧洲和亚洲国家以及中国的有关制定、颁布和实施生物安全管理的作法和机构进行讨论, 重点 介绍了我国现有的生物技术安全管理办法、法则及其运行机制,最后提出了我国未来生物技术安全管理 办法发展的重点。

关键词 生物安全,管理机制,立法状况

Management mechanism of biotechnology safety in China and abroad/SANG Wei_Guo , MA Ke_Ping , WEI Wei

Abstract Management mechanism of biotechnology safety in China and abroad, especially the agencies and function form of biotechnology safety management were reviewed. Methods and organizations of formation , enactment and implement of biotechnology safety at international, continental and national levels were discussed respectively, particularly the methods, regulations and function mechanism in China were introduced. Finally, the future development emphasis of biotechnology safety management of China were suggested.

Key words biosafety, management mechanism, regulations

Author' s address Institute of Botany , Chinese Academy of Sciences , Beijing 100093

\section{引言}

由于生物技术的发展，人类可以通过生物遗传信息的转移来改变植物、动物和微生物 的生物学特性, 这是 20 世纪后期科学史上最伟大的成就之一。遗传工程技术的发展已经 创造并将不断地创造出大量的遗传工程体及其产品,这些产品的商业化必然引起人们对 生物安全的关心(钱迎倩，马克平，1998; 钱迎倩等,1998)。如何有效地管理生物技术产 品是生物安全的一项主要内容。生物技术安全性管理已成为一项新的研究课题,加强生 物技术的安全管理是一项十分迫切的任务。

为了达到趋利避害的目的, 许多国际组织和国家在积极发展生物技术和遗传工程的 同时，也在努力制定和实施有关生物技术安全的法规、条例、指南和规定等。世界上发达 国家和发展中国家的政府部门、商界、科技界、非政府组织及公众舆论出于政治、经济目的 以及对 GMOs (genetically modified organisms 遗传修饰生物体) 的了解程度不同，对 GMOs 释放后可能带来的利益及危险认识不同，或者是科技界学术观点不同或不同学科之间沟 通不够，对环境保护的意识及认识不同等等，在对 GMOs 释放的观点及处理方法上不一致

* 本文是国家 九五”科技攻关项目 中国可持续发展信息共享示范”子专题 生物技术改性活体环境影响评价指标、 风险管理规范研究及生物安全信息开发”的内容( 课题编号 9F925-02-04-05) 
甚至是截然相反的。以下分别论述国际和不同的国家、区域在生物安全方面现有的法规、 指南、管理措施、机构、制度和运行机制等的详细情况。

\section{国际生物安全管理和立法状况}

国际上制定有关生物技术安全的制度、规定和指南等, 最早可以追溯到 20 世纪 80 年 代中期。1985 年,由联合国环境署（UNEP）、世界卫生组织（WHO）、联合国工业组织 (UNIDO) 及联合国粮农组织 (FAO) 联合组成了一个非正式的关于生物技术安全的特设 工作小组，但该小组的工作只是综述生物安全的现状，并没有提出任何建议。1989 年，国 际农业研究磋商小组 (CGIAR) 设立了以制定法规和规范释放为主要目标的 生物技术工 作组” (BIOTASK)。国际经济与合作组织 (OECD) 在 1986 年和 1992 年连续发布了有关 重组 DNA 安全问题和生物技术安全问题的文件 ( Teso,1993)。FAO 于 1991 年 4 月在罗 马召开了植物遗传资源委员会第 4 届会议,所发文件《生物技术和植物遗传资源以及生 物技术守则 III 》中提到经遗传修饰生物体处理和释放的安全准则与法规。

进入 90 年代, 特别是 1992 年联合国环境与发展大会的召开, 更加促进了国际上对生 物安全立法工作的重视，特别是大会由许多国家签署的两个纲领性文件《21 世纪议程》 (国家科委社会发展司编,1992) 和《生物多样性公约》(1)均在有关条款中提到了生物技术 安全问题。在《21 世纪议程》的第 16 章“, 对生物技术无害环境管理” D 款中指出 “: 收集 关于生物安全的数据，并制定一个国际议定原则框架，作为应用于生物技术安全方面的准 则，包括审议达成一项国际协议的需要和可能性”。《生物多样性公约》第 2 条 用语” 中 就将生物技术作为《公约》的一个专门用语来加以说明。在第 8 条 就地保护”的 $\mathrm{g}$ 款中 指出 “: 制定或采取办法以酌情管制、管理或控制由生物技术改变的活生物体在使用和释 放时可能产生的风险，即可能对环境产生不利影响，从而影响到生物多样性的保护和持续 利用，也要考虑到对人类健康的危险”。在第 19 条 (3) 款中又提到 缔约国应该考虑是否 需要一项议定书, 规定适当程序, 特别包括实现知情协议, 适用于可能对生物多样性保护 和持续利用产生不利影响的由生物技术改变的任何活生物体的安全转移、处理和使用, 并 考虑该议定书的形式”。此后, 生物安全议定书的拟定就成为生物多样性公约缔约国大 会一项重要工作内容 到 1998 年 8 月已召开了 4 次关于生物安全议定书的特设专家工作 组会议并拟出了议定书的初稿，供每次缔约国大会讨论。缔约国大会计划到 1998 年 12 月底,最迟不晚于 1999 年 2 月底, 完成生物安全议定书并召开 议定书”实施大会。然 而, 直到 2000 年 1 月 $24 \sim 28$ 日, 生物多样性公约缔约方大会第一次非常会议 (续会) 在蒙 特利尔召开, 法律起草小组才提交了《卡塔赫纳生物安全议定书草案》的终稿, 并于 29 日 晨获大会通过。该议定书计划于 2000 年 6 月 5 日 2001 年 6 月 4 日在纽约联合国总部 开放,供各国和各区域经济一体化组织签署。

联合国环境署 (UNEP) 作为主管生物技术的国际组织, 积极组织制定有关国际生物 安全的法规条例, 在 1995 年组织起草了《国际生物技术安全技术指南》(草案)。经过几 
次有关会议讨论, 1995 年 12 月最后定稿并发布了该指南(1)。指南》将作为一个临时机 制和技术文件，与拟定好的《生物安全议定书》初稿互为补充。《指南》共分 6 章和 7 个附 录，主要内容包括：简介、基本原则和规范、风险评估和管理、国家和区域水平上的安全实 施机制、国际水平上的安全实施机制和能力建设。从某种意义上来讲，该指南是一份各国 都承认的并且具有一定可操作性的技术手册，它将为各国制定生物安全技术指南提供蓝 本和参考依据。

发达国家中美国和加拿大与欧洲联盟对 GMOs 释放的立场是不一致的。前者采取以 产品为基础的监控原则, 是针对生物技术的产品,在原有的相关法规基础上增加对重组 DNA 技术及 GMOs 进行监控的内容。而欧洲联盟则是采取以工艺过程为基础的监控原 则, 只要是 DNA 重组技术得到的 GMOs, 都应接受安全性评价和监控。美国已批准的商 业化 GMOs 的数量远远超过欧洲联盟国家，而欧洲经济联盟在这方面的限制要严格得多。

\section{1 北美地区}

北美地区的生物技术以美国最为发达，代表了世界的最高水平，美国制定的安全法规 和运行机制在全球范围内具有代表性。

美国自 20 世纪 70 年代初就已开始关注生物技术的安全问题,并在有关法规的修正 案中加入了生物技术安全管理的内容。但在 1988 年以前美国还没有一个完全针对遗传 工程有机体环境释放研究与发展的法规, 基本上是沿用以前对毒品、环境等管理的有关规 定(Primary Production Department ,1998)。

自 20 世纪 70 年代初以来, 随着重组 DNA 技术的发明,美国有关生物技术安全管理 的机构也不断发生变化。70 年代中期, 美国国立卫生研究院 (NIH) 成立了一个重组 DNA 顾问委员会来评价由本部门资助的遗传工程研究, 并于 1976 年公布了它的第一套安全准 则, 其主要目的是防止遗传工程有机物从实验室内不经意外泄。后来对该文本不断修订, 于 1986 年 5 月正式发表。随着生物技术的发展, 许多遗传工程研究的内容已完全不属于 生物医学领域,同时管理的目的、对象完全不同了, 因此国立卫生研究院的规定已经不能 满足要求。因而于 1985 年, 在卫生部下成立了附属于美国白宫科技政策办公室的名为 生物技术科学协调委员会” (BSCC) 的机构, 它主要由美国农业部、环保局、食品和药物 管理局、国立卫生研究院和国家科学基金会中的资深政策官员组成。此后直到 1988 年, 美国的生物安全一直由这几个部门来管理。下面介绍各部门在这一时期管理生物技术及 其产品所应用和发布的法律法规。

农业部( OSDA) :美国农业部管理遗传工程的部门是动植物检疫局( APHIS) ,主要管 理动植物疾病和害虫的引入和扩散。管理遗传工程有机体释放的法规有《病毒 - 血清 毒素法》;管理兽医生物学产品的进出口、运输和生产的法律有《联邦植物害虫法》、《植物 检疫法》等。农业部在 1986 年建议并于 1987 年 6 月确立了一个专门针对遗传工程有机 体的规定，即《通过遗传工程所产生或改变的属于植物害虫类有机体的引入规定》。

环保局 ( EPA) : 有关遗传工程微生物环境释放的法规有两个: 1 )《联邦杀虫剂、杀真

(1) UNEP ,1995. UNEP International Technical Guidelines for Safety in Biotechnology. United Nations Environment Programme. Nairobi, Kenya 
菌剂、杀鼠剂法》(FIFRA)，该法禁止扩散、销售和使用尚未在环保局登记的农药，用作农 药的微生物也在其管理范围 2)《毒物控制法》,非农药微生物在其控制之下, 用于非农药 以及非农业、医学用的商业微生物的管理，它实际上是一个填补空缺的法规，把微生物和 它的 DNA 看作是一类化学物质。由于这两类法规不是专门针对遗传工程有机体的, 因此 在应用过程中产生了很大的困难，所以在 1988 年 6 月，环保局制定了一个专门适用于遗 传工程有机体的管理规定。

食品和药品管理局 (FDA) :食品和药品管理局运用《公共卫生服务法》和《联邦食品、 药物和化妆品法》来管理遗传工程产品, 诸如食品添加剂、药物等的安全性和有效性。

自 1988 年之后, 美国有关遗传工程体及其产品安全主要由 USDA、FDA 和 EPA 来管 理, 特别是农业部的动植物检疫局 (APHIS) 成为管理植物新品系安全测试和商业化的主 要部门。政府强调在新的生物技术产品研制过程中，各部门间密切协作、互通信息是生物 技术产品安全的有力保证。美国动植物检疫局的《生物安全法》1987 年生效, 这个法规规 定了遗传工程体的出口、州际间运输、大田试验的程序和方式。近来美国发布了针对不同 类型遗传工程有机体的安全管理条例和指南,这些条例和指南在生物技术安全管理中发 挥了重要作用。

总体来讲, 由于美国具有先进的生物技术，因而对生物安全问题比较重视并及早开展 研究，其机构体系、管理制度、法规和指南等比较完善，是世界各国制定同类法律、法规的 样板。

加拿大是北美地区另一个生物技术比较发达的国家,负责生物安全管理的联邦机构 有三个, 即加拿大食品检察署、加拿大卫生署和加拿大环境署。1992 年, 加拿大卫生署制 定了《生物技术产品规则框架指南》，该指南的一个中心内容是 尽量利用现有的法律和 法规机制来管理生物技术产品以避免重复”。因此加拿大食品检察署利用《种子法》管理 新品系植物，《饲料法》管理具有新品质的饲用微生物、发酵产物和植物，用《肥料法》管理 利用生物技术方法得到的有机肥料，《动物健康法》管理与动物遗传操作有关的生物体。 经遗传修饰的动植物产品和微生物受《植物保护法》和《动物健康法》的制约。负责食品 安全的加拿大卫生署利用《食品法》和《药品法》来管理新食品, 利用《害虫控制法》来管 理与害虫控制有关的产品。对于转基因动物的进出口限制和食品安全由食品检查署和卫 生署来共同管理，只是侧重点有所不同。以上法案没有涉及到的生物技术产品均由环保 署管理，它所利用的法规有《加拿大环境保护法》和《新物质声明法》( Primary Production Department ,1998)。

美国和加拿大的生物安全法规和机制基本上代表了整个北美地区，但这两个国家的 根本差别是:美国针对生物技术发展的特点制定了新的指南和法律;加拿大尽量利用现有 法案，从这一点来讲美国的作法有较大的优势。

\section{2 欧洲}

欧洲经济联盟及其成员国在 20 世纪 80 年代初期开始考虑评估和管理遗传工程有机 体的环境释放。1984 年 2 月欧盟建立了一个生物技术指导委员会，以协调欧盟内生物技 术政策。1986 年曾召集各国官员讨论有关规定、协调各项活动、控制发展水平及研究工 业废物的管理及突发事件的应变以及有计划的环境释放授权等。在欧盟内部，所有通过 
转化手段得到的作物都受到 环境释放和商品化生产” (90/220/EEC) 和 封闭使用” (90/ 219/EEC) 指令的管理，作食品用途的遗传修饰生物体则按 1997 年新的《食品管理法》进 行管理。委员会指令 93/114/EEC 在原有法规 70/524/EEC 的添加剂类别中增加了一类 含有 GMOs 的添加剂。

英国在 1986 年 4 月公布了一个已经发展了的所谓自愿的准则 鼓励个人在计划释放 遗传工程有机体前与卫生和安全官员联系, 要求科学家在进行遗传实验时通知有关人员, 对一些危险性较大的实验应呈交单独的申报书。实验室内进行的基因转化工作，必须按 照 1992 年颁布的《遗传修饰生物体管理法》进行申报“封闭使用” 条款于 1996 年和 1998 年修正)。每个研究单位都有一个遗传修饰安全委员会对申报提出建议，然后由卫生与 健康执行委员会 (HSE) 和其他政府部门进行评审,这些部门包括环境、运输和区域局 (DETR)、农渔食品部 (MAFF)、卫生局 (DH)、苏格兰事务部 ( SO) 和威尔士事务部（WO） 等, 遗传修饰咨询委员会 (ACGM) 也会参加。进行环境释放时要按照 1992 年颁布的《遗 传修饰生物体管理法》进行申报“有目的释放”条款于 1995 年和 1997 年修正), 申请包 括 GMOs 的描述、释放的细节和风险评价。该申请提交给 DETR, 并要经其他部门( HSE, $\mathrm{MAFF}, \mathrm{DH}, \mathrm{SO}, \mathrm{WO}$ 等) 评审, 环境释放咨询委员会 ( ACRE) 也参加评审。如果要进行商 品化生产, 则要按如上程序批准后, 通过欧盟转交到其他成员国进行评审。

荷兰生物安全管理的机构有环境部、GMOs 执行办公室、遗传修饰委员会和一个秘书 处，环境部负责对所有与遗传修饰生物体相关的活动颁发许可证，负责制定遗传修饰方面 的政策，具体处理由 GMOs 执行办公室操作，遗传修饰委员会的建议由一个秘书处汇总 (Bergmans ,1999)。

德国把重组 DNA 实验分为四类, 遗传工程有机体的环境释放被列在禁止的一类, 但 研究人员可作为一种例外申请这类研究实验。1984 年成立了一个国会的委员会研究基 因技术有可能产生的对科学、社会和法律的影响，并发表了一个专门报告，建议 5 年内暂 停环境释放遗传工程病毒 (人、兽用疫苗除外) 和微生物 (指加入外源基因的)。1990 年 7 月 1 日德国《基因工程法》正式生效，规定 GMOs 的释放和基因工程产品的上市由联邦卫 生局 (BGA) 审批。BGA 设有生物安全中央委员会, 负责提供与安全事务相关的专家意 见，特别是对有关活动的封闭等级划分和释放的风险评估提供咨询 (朱守一,1999)。

丹麦在 1986 年已颁布一项法规, 防止蓄意释放任何重组 DNA 产品以及任何基因剪 接的有机体或细胞杂交产品。法规规定除非环境部批准，禁止以上任何一类的实验。

法国 1987 年在农业部的管辖权限范围内建立了一个由 15 位专家组成的小组来逐项 评审有计划的环境释放实验并考虑建立新规定, 有关使用重组 DNA 技术实验的通知还必 须呈交给研究和高等教育部。

瑞典在 1984 年成立了一个专门的委员会研究是否需要对重组 DNA 研究加强管理, 该委员会认为国家现有的职业卫生和环境保护监督是恰当的,不必再加强管理。

2.3 亚洲、拉丁美洲等

亚洲和拉丁美洲大都是发展中国家, 它们在生物技术方面相对落后。随着发达国家 生物技术进步的不断影响和渗透以及国际社会对发展中国家生物安全问题的关注,发展 中国家在发展生物技术的同时也开始制定和发布有关生物安全的法律和法规。 
在亚洲，印度科学和技术部在 1990 年颁布了《重组 DNA 安全指南》;埃及在 1994 年 由农业和土地开唇部、农业研究中心和农业遗传工程研究所共同制定并颁布了《生物安 全一一法律和指南》,成立了生物安全委员会,分为国家生物安全委员会及研究单位生物 安全委员会两级。印度尼西亚在参照其他国家生物安全法规主要是在澳大利亚法规的基 础上，于 1997 年发布了《生物技术安全指南》(Primary Production Department ,1998)。

日本制定了两个针对重组 DNA 试验的准则，即《综合性大学研究设施中重组 DNA 试 验准则》(教育部制定) 以及《重组 DNA 试验准则》(科学技术部制定, 适用于除大学以外 的其他所有研究机构)。有 6 个针对工业应用的准则正在实施之中 : 1) 《重组 DNA 生物 在农业、渔业、林业、食品工业和其他相关工业中的应用准则》2）《重组 DNA 生物在饲养 业中应用的安全评估准则》 3 ) 《重组 DNA 技术在饲料添加剂中应用的安全评估准则》; 4)《重组 DNA 技术生产的食物和食品添加剂准则》5)《重组 DNA 技术在制药等行业中 的应用准则》,6)《重组 DNA 技术工业化准则》(Hino ,1999)。

在拉丁美洲和加勒比海地区，巴西、古巴和墨西哥均以美国国立卫生研究院的规程为 基础, 制定了在实验室内进行遗传工程研究的《生物安全指南和标准》( Naredia \& Bedford ,1993) 这些指南和标准是以美洲农业合作机构为主起草和实施的。巴西科学和技 术委员会很早就发布过生物安全指南, 墨西哥也在其健康法案中充分考虑了遗传工程技 术的问题，这三个国家均成立了国家级生物安全委员会。另外拉丁美洲的阿根廷、哥斯达 黎加和智利也发布了关于遗传修饰体向环境转移释放的法规。

由此可见，发展中国家正在制定和不断完善它们的生物安全法规，形成自己特有的机 构和管理机制。这种趋势反映了国际上对生物安全的认识不断加深并且给予它越来越多 的重视。

\section{我国生物安全管理和立法状况}

中国是一个发展中国家,又是一个生物技术比较发达的国家。20世纪 80 年代后期 到 90 年代初期,生物技术在中国政府的密切关注和优先资助下得到了迅速发展，并且被 认为是解决粮食问题的一个主要方法和高技术革命的一项主要内容。但由于认识上及其 他方面的种种原因，生物安全的研究和实践活动远远落后于生物技术的发展。进入90 年 代，中国政府的有关部门开始积极行动解决生物安全问题，如成立了相应的组织来管理生 物安全, 有关部门已把有限的研究经费用于生物技术安全研究, 制定有关的法律法规和指 南等。由国家环保局牵头，农业部、教育部和科学院参加，UNEP/GEF 资助的《中国生物 安全国家框架》目前已经制定完毕。国家框架共分四部分 (国家生物安全管理政策体系 框架、国家生物安全管理法规体系框架、遗传工程体风险评估和风险管理的技术准则框架 和生物安全管理国家能力建设) 以及 10 个附录 (国家环保总局 2000)。

\section{1 机构和机制}

1993 年, 在国家科学技术委员会领导下成立了国家生物遗传工程安全委员会,由来 自卫生部、农业部、轻工业部的专家组成，负责医药、农业和轻工业部门的生物安全。此时 生物安全的主管部门是国家科学技术委员会, 它要求除成立国家生物安全委员会外, 与生 
物安全有关的各部委和单位也要成立相应的生物安全委员会。1994 年以后,由于农业生 物技术特别是转基因作物和转基因饲养动物的发展，农业部成为生物技术安全管理的主 要部门。近年来，随着人们对环境问题的关心，经遗传修饰的生物在释放后的环境安全问 题引起了重视，国家环保总局作为主管全国环境问题的政府部门开始介入生物安全管理 事物。特别是《生物多样性公约》各次缔约国大会中要求拟定《生物安全议定书》,环保总 局作为中国政府的主管单位代表参加议定书的谈判，同时又作为联合国环境署《国际生 物技术安全技术指南》在中国的实施机构, 完成了《中国生物安全国家框架》的制定。目 前，在中国负责生物安全的部门有国家科学与技术部、国家环保总局、农业部、卫生部、国 家医药管理局等。

\section{2 与生物安全有关的法规}

中国有关生物安全方面的第一个法规是针对基因工程药物制定的，即 1990 年制定的 《基因工程产品质量控制标准》。标准规定,基因工程药物的质量必须满足安全性的要 求。该标准只对生物技术产品的品质加以限制，对基因工程实验研究、中间试验及应用过 程等的安全性未做具体规定。我国生物药品研究和临床试验是按照新药和新产品开发管 理办法规定进行的。

1993 年 12 月 24 日国家科学技术委员会发布了《基因工程安全管理办法》(1),农业部 以其为基础制定了《农业生物基因工程安全管理实施办法》(2),于 1996 年颁布实施。

国家科委的管理办法是一个总纲 共由 6 章组成，规定了我国基因工程工作的管理体 系, 按潜在危险程度将基因工程工作分为四个安全等级, 并规定了审批权限。农业部的实 施办法由 6 章和 6 个附录组成, 内容较为具体、针对性强, 具有较好的操作性, 在结构上与 科委的管理办法一样。农业部的管理办法不包括医用遗传工程药物，这类药物由卫生部 按照新药审批办法进行管理。

\section{3 运作机制}

1993 年国家科委发布的《基因工程安全管理办法》，对从事基因工程工作在实验室阶 段、中间试验阶段以及工业化阶段的安全等级的划分、批准的部门以及申报及批准的程序 都作了规定。

1996 年农业部颁布的《农业生物基因工程安全管理实施办法》是一部较完善的实施 办法。为了贯彻执行《实施办法》,农业部成立了农业生物基因工程安全委员会和农业生 物基因工程安全管理办公室, 于 1997 年发出《关于贯彻执行 农业生物基因工程安全管 理实施办法”的通知》(3。针对抗虫棉在国内的发展，农业部在 1997 年特别发出了《关于 加强转基因抗虫棉安全和种子管理的通知》(4), 1998 年发出了《关于进一步加强农业生物

(1) 中华人民共和国科学技术委员会,1993. 基因工程安全管理办法

(2) 中华人民共和国农业部,1996. 农业生物基因工程安全管理实施办法

(3) 中华人民共和国农业部, 1997. 关于贯彻执行 农业生物基因工程安全管理实施办法” 的通知

(4) 中华人民共和国农业部,1997。关于加强转基因抗虫棉安全和种子管理的通知 
基因工程安全管理的通知》 (1),1999 年又发出了《关于加强农业生物基因工程安全性评价 申报工作的通知》(2),明确了农业生物基因工程体及其产品中间试验和环境释放规模的上 限 :

\begin{tabular}{lll}
\hline 类别 & 研究阶段 & \multicolumn{1}{c}{ 规模上限 } \\
\hline 植物 & 中间试验 & 总规模不超过 2 亩,布点不超过 2 个 \\
& 环境释放 & 总规模不超过 20 亩,布点不超过 10 个,禁止在相同生 \\
& & 态区重复布点 \\
& 中间试验 & 布点不超过 5 个,每点不超过 15 亩 \\
植物用微生物 & 环境释放 & 布点不超过 4 个,每点不超过 6000 亩 \\
& 中间试验 & 限制在一个省区内, 进行 $3 \sim 5$ 批中试 产品的应用, 大 \\
兽用微生物 & & 动物不超过 1000 头, 中小动物不超过 10000 头 (只), \\
(主要指疫苗) & & 禽类不超过 20000 羽 (只),鱼不超过 20000 尾。 \\
& &
\end{tabular}

《实施办法》在安全等级和安全性阶段角度从受体生物基因、操作和遗传工程体三个 方面来进行确定，考虑得比较全面。申报及审批方面，对实验研究、中间试验及商品化生 产的审批权限都有了明确规定。针对动物、植物、微生物、水生生物遗传工程体的审批, 全 国基因工程安全委员会分别成立了相应的评审小组。《实施办法》附有详细的申报表，在 申报审批程序上规定每年召开两次全国基因工程安全委员会会议进行审批，对不同的遗 传工程体及其产品的安全性评价有附件作了较明确的说明, 最后一部分还考虑到了安全 控制措施。应该说是一个具有可操作性的实施办法。《实施办法》还规定国外研制的农 业生物遗传工程体及其产品到我国境内进行中试、环境释放或商品化生产，必须持有该国 允许进行同类工作的证书。至于更详细的关于转运及进出口等方面未包括在内。农业部 的《实施办法》颁布后, 至今已受理农业生物基因工程安全评价申报书 195 项,批准 158 项, 其中商品化生产 26 项 环境释放 58 项，中间试验 75 项。

\section{4}

\section{存在的问题及讨论}

我国是世界上最早大面积释放转基因作物的国家之一。1992 年转基因双抗烟草释 放面积在河南省达 $8000 \mathrm{hm}^{2}$,1994 年我国转基因烟草释放面积达 100 万 $\mathrm{hm}^{2}$, 到 1997 年 我国转基因作物的面积虽然在国际上仍排在第 2 位，但发展速度已远不如美国、加拿大、 墨西哥、阿根廷等国家 (钱迎倩等,1999)。而且美国的转基因抗虫棉已在我国商品化种 植 3 年。在这种国际形势下，我国加强转基因生物的研究和开发已成为必然。据报道，目 前国内被批准进行商品化生产的有抗虫棉、延熟番茄、抗病毒番茄、抗病毒甜椒和改变花 色的矮牵牛等 3 。其中除了抗虫棉外, 其他的几种均未达到实际意义上的商品化。究其 原因，除了转基因植物生物安全评价体系滞后外，管理法规运作机制薄弱也可能是其中的 


\section{一个重要因素。}

我国生物安全管理滞后于生物技术的发展, 表现在从社会到各级领导部门、从公众甚 至到科研人员的生物安全意识都比较差。我国的转基因作物 (抗病毒转基因烟草) 大面 积释放是在 20 世纪 80 年代末期, 90 年代初以后也陆续有其他作物相对大面积的释放， 成为世界上大面积释放最早的国家之一，但只有个别报道涉及到转基因作物释放后的跟 踪。1993 年, 国家科委颁布了《基因工程和安全管理办法》,1996 年,农业部又颁布了《农 业生物基因工程安全管理实施办法》, 但由于经费或其他种种原因, 部分研究人员在填写 申报材料时不够严谨, 部门利益保护的作法在生物安全管理中的问题也时有发生。从生 物安全管理来看, 目前国内还存在不少问题, 在一定程度上影响着生物技术的发展。这些 问题需要进一步研究解决。

生物安全管理需要建立健全的管理机构, 由于生物技术覆盖的领域很广, 安全管理涉 及的行业和部门较多，建议从国家的角度制定一部统一的生物安全法规, 要注意使条款尽 可能地清楚,有较强的可操作性,例如转基因食品是否需要标签等必须在法规中明确规 定。各个部门也应当根据其部门生物技术的特点制定部门的生物安全技术条例，当然，建 议的可行性有待进一步探讨。

另一方面，要通过媒体向广大群众宣传、普及生物安全知识,让群众成为生物安全管 理的知情者。主管部门要努力协调与生物技术安全有关各部门的工作 ,使管理部门的工 作更加有效。

\section{参 考 文 献}

国家科委科技发展司编,1992. 21 世纪议程. 见 联合国环境与发展会议论文汇编. 北京 科学技术出版 社

钱迎倩,1994. 生物多样性与生物技术.中国科学院院刊 2 :134 149

钱迎倩，马克平，1998. 经遗传修饰生物体的研究进展及其释放后对环境的影响. 生态学报, 18(1):1 9 钱迎倩，田彦，魏伟，1998. 转基因植物的生态风险评价. 植物生态学报 22(4) 289 299

钱迎倩，魏伟，田彦，马克平，1999. 转基因作物在生产中的应用及某些潜在问题. 应用与环境生物学报， 5 ( 4 ) : $427 \sim 433$

朱守一 ,1999. 生物安全与防止污染. 北京: 化学工业出版社 ,1 264

Bergmans , 1999. Risk assessment practice in the Netherlands. In : Xue D Y , Virgin I(eds. ), Regulation and Practice on Biosafety. Beijing : China Environmental Science Press , $45 \sim 51$

Hino A , 1999. Safety assessment frameworks for transgenic crops in Japan. In : Xue D Y, Virgin I(eds. ), Regulation and Practice on Biosafety. Beijing : China Environmental Science Press , $24 \sim 27$

Naredia K , Bedford B , 1993. The USAID Latin America Caribbean Region Biosafety Workshop , Oracabessa. Jamaica

Primary Production Department, 1998. Regulations for Agricultural Products Derived from Biotechnology. Singapore : KH Biotech Services Pte. Ltd

Teso B , 1993. OECD International Principles for Biotechnology Safety , Agro_Food Industry Hi_Tech , 4 :27 31

国家环保总局 2000.中国国家生物安全框架. 北京 :中国环境科学出版社 